\title{
Research on the Disaster-prevention System Adaptation Strategies for Urban High- rise Community
}

\author{
Lixin LI \\ School of Civil Engineering \\ Shenyang Jianzhu University \\ Shenyang, China \\ e-mail: lilixin1966@163.com
}

\author{
Dan ZHU \\ School of Civil Engineering \\ Shenyang Jianzhu University \\ Shenyang, China \\ e-mail: 1396926559@qq.com
}

\author{
Xingkai JIN \\ China Construction Third Engineering Bureau Group \\ Co. Ltd. (Northeast) \\ Shenyang, China \\ e-mail: 786606470@qq.com
}

\begin{abstract}
Due to the intensive construction of high-rise buildings, population concentration, in the face of disaster increasingly vulnerable, while the community as the city's most basic disaster prevention unit, community security largely affects the safety of the whole city. However, our country city existing high-rise community generally lack the system of disaster prevention planning, design and construction, most of the high-rise community, there are many security risks, once a disaster occurs, extremely easy to cause disasters expand and spread, resulting in heavy casualties and huge economic losses. Therefore, the transformation of disaster prevention and mitigation of high-rise community has aroused people's concern. The high-rise community as the research object, first of all to the research object were in-depth analysis, and through large numbers of field investigation, summarizes the status of China's urban high-rise community and the issue of prevention, analysis of the residents in disaster psychological and behavioral response, construction of the disaster prevention of urban community transformation system to guide the specific community disaster reconstruction strategy.
\end{abstract}

Keywords-high-rise building; community disaster-prevention; disaster prevention adaptation system; adaptation strategies

\section{RESEARCH PURPOSE}

China's residential community in the planning and design and construction of the community to consider the construction of community disaster prevention system, but also, after the Wenchuan earthquake, China has developed and implemented a new seismic code, A large number of old communities do not meet the requirements of the existing norms, there are many security risks, the task of disaster prevention and mitigation is also very heavy [1]. Although our country also gradually renovate old community, its transformation in fault maintenance, energy conservation, landscaping, residential environment and living space transformation, few of the existing community disaster prevention and transformation of the system. Even, into the system, into the system of community disaster prevention and mitigation of theory research is rare, there are many research is focused on the structure of seismic retrofit, building fire protection, such as a single. Therefore, this paper proposes the construction of disaster prevention community transformation system, and from the three aspects of the refinement of community disaster prevention space system, the construction of disaster prevention system and community disaster management and rescue system of city disaster prevention is the best continuation and implementation.

\section{A. Problems in the Existing Research}

- There are many researches about urban disaster prevention, and there are few systematic researches on community disaster prevention. At home and abroad for urban disaster prevention research has been more extensive and in-depth, urban disaster prevention planning has a more perfect laws and regulations and technical indicators. And the community as the city's basic disaster prevention unit, the system of disaster prevention and mitigation research is very few.

- Lack of research on the concept of disaster prevention from the design point of view. Architects and planners rarely involved in disaster planning, resulting in our country all levels of planning, design and construction practice lack of reflected from the point of view of design [2], the system of disaster prevention ideas and material of disaster prevention space and disaster prevention facilities generally lack of configuration.

\section{B. Deficiencies in the Existing Research}

- For residential areas, such as energy conservation, landscaping [3], the transformation of space and other research and practice more, less on the transformation of community disaster prevention system. 
- Study on the strategy of community disaster prevention and mitigation in the lack of system. In our country, the research on the evaluation index system of community is mostly focused on green, ecological, livable and so on. The research on the relationship between community safety and disaster prevention and mitigation index system is a blank.

\section{DisAster Challenges OF URban High-RISE COMMUNITY}

\section{A. Complex Factors, It Is Difficult to Effectively Control}

Affected the way complex and diverse, and easy to interact with each other or the formation of secondary disasters. The increasing size of the high rise community and its physical form and the high concentration of the living population make the elements and disaster affected by the complex and diverse and easy to affect each other or the formation of secondary disasters--High-rise residential buildings are vulnerable to earthquakes, fires, storms, explosions and attacks of war; Three-dimensional space systems (such as general construction of community underground space)to become susceptible to fires, floods and storm against the elements; highly dense and numerous population faces the threat of the spread of disease. Visible, the main affected elements, such as high-rise buildings, underground space and infrastructure vulnerable spots, and the affected easily cause a chain reaction, effective fortification is extremely difficult.

New materials and new technologies have brought new challenges to the disaster. At present, the market filled with a large number of the intricacies of new materials, to the disaster has brought new problems, such as CCTV building, the use of new insulation materials resulting in the building fires are difficult to extinguish. In addition, building construction is also promoting a variety of new technologies, especially high-rise residential building, the application of a lot of new technologies, and some of the new technology and even challenge the technical limit [4]. New materials, new technology applications are not standardized guidance and practical reference, and many of their disaster prevention issues have yet to be further studied.

The probability of human induced disasters increased. Due to the high level of the community, a large population, so that the risk of human caused disaster will be increased. According to the statistics of our country, one of the most frequent space in the residential fire is the bedroom, and the bedroom fires are caused by smoking. With the improvement of our country's economic level, more and more types of household appliances, old and high-rise community electrical wiring aging, electrical overload operation or improper use of electrical appliances is also very easy to cause fire.

\section{B. It Is Difficult to Save the Disaster after Disaster}

First, because many of the high-rise community scale large and residential intensive, community road width of less than or pavement was parked misplacing car occupied resulting in post disaster rescue vehicles can quickly arrive at the disaster site timely relief. Secondly, the high-rise building fire spread quickly, when the house is higher after the fire, because the fire fighting vehicles are highly limited, from the outside of the building is often not timely and effective control of the fire. And many of the existing highrise residential fire equipment and facilities are inadequate, or the lack of maintenance and management and can not be used properly, which led to the construction of the building can not effectively fight fire personnel.

\section{Emergency Evacuation Organization}

Large high-rise community covers an area of large, complex structure, once the occurrence of large-scale disasters, the evacuation of residents level long distance, community limited road width and open space, it is difficult to guarantee the residents quickly safe evacuation escape to the community security space. For example, the disaster caused by the collapse of high-rise buildings, collapsed buildings are very easy to plug the road near the community, resulting in the evacuation congestion. Even worse, the high-rise residential buildings to the residents to evacuate to bring a lot of negative factors: Because of the high building height, the vertical distance of the residents in high-rise residential buildings is longer; Dense personnel are also likely to result in the evacuation of people have difficulty. And high-rise residential smoke is also more complex than the multi-storey residential, and its internal flue gas flow is also faster, how to effectively prevent smoke and smoke exhaust is one of the important factors to ensure the safety of residents evacuated.

\section{ANALYSIS ON THE BASIC RESEARCH RESULTS}

\section{A. Analysis of Urban High-rise Community Disaster Prevention in 60s and 1930s}

In this period, the basic construction of our country is a multi-storey residential, there are few high-rise residential, high-rise residential buildings in the period is usually only one or two, can not be called community. Generally its disaster prevention space and disaster prevention channel should be based on the surrounding urban space and the road conditions; the transformation of the city needs to rely on urban disaster prevention and transformation. During the period of the original equipment of high-rise residential facilities aging serious, and build rarely equipped with fire fighting equipment and facilities, and usually have been carried out energy-saving reconstruction, building image beautification transformation, but few are special disaster reconstruction, it is a great security risk [5].

\section{B. Analysis of Urban High-rise Community Disaster Prevention Problems in 90s and 1970s}

The status of dangerous sites and dangerous building in the surrounding of the community and the community. The status of evacuation space around the community and the community [6]. Generally, the period of high-rise residential scale will not be particularly large, the general lack of housing in the residential space. The status of evacuation channel in the neighborhood and community. In the period of the community is generally only according to the 
requirements of the fire to build a basic fire lane, the road is generally narrow. Also old community building parking set a serious shortage, at the side of the road in the community even the sides often stop with residents of private car, resulting in fire lane can use the effective width is insufficient, some fire lane even jammed. Communities in the event of a disaster, rescue vehicles can not quickly enter the community.

Configuration and maintenance of equipment and facilities for disaster prevention in community building. The period of the community is limited to the economic situation and the standard requirements, disaster prevention equipment and facilities are generally inadequate. Generally only equipped with fire hydrant, generally there is no allocation of emergency lighting, emergency broadcasting, fire detector, automatic sprinkler fire extinguishing systems. Many of the fire fighting facilities are not used for long term maintenance. Due to the construction of a long period of time, wires, pipelines and other serious aging, a large fire hazard.

\section{Analysis of Questionnaire Survey Results of Urban High-rise Community}

From the survey found that most of the residents are only on the daily life of a certain accumulation of security knowledge, only a small proportion of residents participated in a special safety education or participated in a formal emergency evacuation exercise; Many residents of disaster awareness, it is not clear and the surrounding communities are communities within the refuge space and safe evacuation routes, didn't even have the sense to a clear understanding of their daily living residential all exit and evacuation route; A lot of residents did not maintain the concept of fire equipment and facilities, and some residents even built a private build, take the exit or smoke exhaust balcony; Residents in the home decoration, most residents have more and more attention to environmental protection, but only a small proportion of the residents pay attention to the fire performance of decorative decoration materials.

\section{Characteristics of Behavior Psychology and Emergency Response of Community Residents}

From the research and the domestic and foreign existing research can be found: community residents in disaster in addition to panic, the nearest evacuation, the preferred choice of familiar channel and places, toward the open area and other common, also has some properties of the different in office buildings, schools, factories and other buildings and places, as follows:

The age difference of the victims is one of the important factors affecting the speed of evacuation; the evacuation rate of young people and middle-aged people is faster than that of the elderly, infants and young children. Age will also affect the sensitivity of the disaster response to disasters and response measures [7]. Age will also affect the sensitivity of the disaster response to disasters and response measures. Young people, middle-aged people are relatively strong response to the disaster; the disaster emergency response is also more conducive to the smooth escape. In addition, the probability of successful evacuation of the population at different ages in the disaster is not the same.

\section{The Strategy OF High-RISE COMMUNITY DisASTER PREVENTION SPACE SYSTEM TRANSFORMATION}

\section{A. Community Disaster Prevention Space System}

Disaster isolation space system: Community disaster spatial isolation system, mainly including square community, community protective greenbelt, sanitary isolation belt, waterfront space, large-scale road and fire resistance and good anti-seismic construction of buildings and so on. Between the community disaster prevention unit set of disaster prevention space can effectively prevent the spread of the flood, fire, storm, infectious diseases, etc. many kinds of disasters, diffusion, thereby reducing disaster losses.

Emergency evacuation space system: The emergency shelter space systems, including square, green, schools, stadiums and other has a certain scale of open space, place should also is equipped with the necessary emergency shelter facilities, to meet the needs of shelter residents and temporary life. After the disaster, people first will nearby for emergency places of refuge space, all rescue activities must be to refuge space based, so the construction of a perfect emergency refuge space system is a spatial basis for the construction of the community disaster prevention space system.

Lifeline engineering system: Lifeline engineering is the central nervous system to ensure the normal operation of the city. The lifeline engineering in the community field mainly involves five aspects: water supply, drainage, gas supply, power supply and communication. Each community should first have a relatively complete lifeline engineering system. Each community should first have a relatively complete lifeline engineering system [8].These infrastructures play an important role in daily life and they are also indispensable in disaster. Community lifeline engineering system is a basic engineering facility system to maintain the normal life of the community residents, and its disaster prevention performance is related to the impact of disaster on other projects and the process of community disaster reconstruction. When disaster occurs, many facilities and equipment in lifeline engineering system have high economic value, and the damage of lifeline engineering system will result in great economic loss. Moreover, the destruction of lifeline engineering system will also cut off the survival ability of the community, thus hinder the work of disaster relief work, and even its destruction will directly lead to secondary disasters, increase disaster casualties and losses.

Fire space system: Fire system space and community disaster prevention space system is an important part, mainly including fire safety layout, fire truck passageways, fire station, fire water supply, fire fighting equipment and fire communication content, in response to the community fire or other emergency.

Emergency material reserve space system: Currently our country community level emergency material storage 
building fewer, after the disaster, usually need to from urban reserve institutions large-scale deployment, transport emergency supplies, occupied a large number of rescue personnel, reduce the efficiency of the rescue. If the community rescue channel is blocked, relief supplies can not be served in a timely manner.

\section{B. High-rise Community Spatial Structure and the Strategy of Disaster Prevention and Reconstruction}

Different community spatial structure and morphology has a space of their respective characteristics, this paper according to the centralized structure, belt structure, free dispersion type structure and organic network structure of the feature space and the issue of prevention. A summary of the main disaster reconstruction strategy.

\section{1) Strategy of centralized structure disaster prevention:}

In the centralized spatial structure of the community structure center set up a large square or primary school as a long-term community emergency shelter. The service radius of the center shelter should be between $500-1000 \mathrm{~m}$, at least among the 0.5-1.0ha, and the refuge should be equipped with perfect disaster prevention and disaster relief facilities. Communities should be balanced within a reasonable amount of a reasonable number of emergency shelter, its size should not be less than 0.05 ha.

Sufficient width and traffic of the disaster prevention channel. If the main evacuation function is assumed to be greater than $15 \mathrm{~m}$.According to the size of the community within the community should set a circle or ring type community evacuation channel, its width should be about $12 \mathrm{~m}$.

Community size and population density should be controlled within a reasonable range, to ensure that residents reach an emergency shelter for no more than 5 minutes, that is, within walking $300 \mathrm{~m}$ to reach; Residents have reached the limit of refuge in the Community Centre for no more than 20 minutes, that is, the control of walking distance in $800-1000 \mathrm{~m}$.

2) Strategy of disaster prevention and reconstruction with belt structure:

Belt type structure needs in the longitudinal main ridge axis and transverse evacuation routes cross node at set refuge space, and the scale can be in 0.1-0.5ha, position can be combined with the uniform distribution of the bus station in order to guarantee the average of refuge resources.

Belt type community structure transverse disaster prevention and rescue channel band is generally set in the line of traffic and perpendicular to the longitudinal direction of the main shaft, the mutual spacing should not be more than $250 \mathrm{~m}$, width of not less than $12 \mathrm{~m}$, to avoid blocking the transverse passage of the rescue and evacuation.

Belt type structure of the size of the community also should not be too, general community at any point of arrival and the nearest emergency evacuation sites (usually a horizontal network of cross node) walk should not exceed 5 minutes; community at any point arrived at the axis of the main ridge distance should not be greater than $1.5 \mathrm{~km}$ or walking should not be more than 30 minutes.

\section{3) Adaptation strategies of free distributed structural} disaster prevention:

Because there is no obvious refuge center, the cross points of the main road of the balanced distribution should be set up to a certain scale evacuation space.

Free distributed structure of the community to have a good place of refuge for the community, the general requirements of at least two or more of the disaster relief channel and its associated.

Free dispersion type community structure of traffic network to have sufficient width, major disaster prevention and rescue channel width of not less than $12 \mathrm{~m}$, community evacuation channel width of not less than $10 \mathrm{~m}$.

4) Strategy of organic network structure disaster prevention and reconstruction:

Organic unit of organic network community structure between the open space, green or water of the square as a result of the disaster isolation belt or in long-term shelter, various organic unit between the open areas of the formation of community disaster prevention space network, to effectively prevent the spread of the disaster [9].

\section{Management And Rescue System}

\section{A. Establish Specialized Community Emergency Rescue Team}

In addition to the fire, medical care has more professional disaster prevention and rescue team, the other is by the public security, the army to assume an emergency rescue mission. Visible, compared with foreign countries, China in the disaster relief team construction, or should further build to public security, fire protection as the main force, each system, industry and professional rescue teams as the basic force, police, troops and the militia emergency detachments for strength to support the professional rescue teams system, and gradually establish a "national, regional, urban and community" all levels of professional rescue teams.

In particular, as a professional community emergency rescue teams, should develop a suitable, effective and perfect emergency training program, to strengthen the professional training.

\section{B. Strengthen Disaster Prevention Education for Residents}

Disaster prevention education in our country is almost a blank, and community disaster prevention management and command center as the most widely distributed disaster prevention agencies should first do a good job in the work of disaster prevention education. Disaster relief training should be the main emergency and first aid training, its main content is to help people to improve the ability of dealing with emergencies, forming good psychological quality, to prevent the emergence of chaos, reduce unnecessary damage, all losses will be reduced to a minimum. Disaster training includes all sorts of unexpected events, the big earthquake, terrorist attacks, fire, flood and disaster problem, small processing to the family in various accidents, protection of various chemicals, electric shock, poisoning, all kinds of unexpected disease first aid and so on. Anyway, 
the purpose of disaster prevention education is to let people understand should do what kind of disaster preparedness at ordinary times, in an emergency situation how to hedge, if necessary, how to carry out the evacuation, how to carry out self-help and mutual aid.

\section{MAIN RESEARCH CONCLUSIONS}

Due to the loss caused by the current disaster is huge, spread wide, social impact, in-depth discussion of disaster prevention and mitigation, improve defense capabilities is particularly urgent. As the most basic unit of disaster prevention, the research of disaster prevention and mitigation can not be ignored. In our country, there is a general lack of system of disaster prevention planning, disaster prevention capacity to be upgraded. Therefore, through in-depth study and system analysis, the following conclusions are drawn:

1. Spatial coping of multiple disasters:

Building a safe community is the goal of community disaster prevention and mitigation. Communities may suffer from various types of disaster causing factors, each of which is related to each other and influence each other. Therefore, he transformation of community disaster prevention and mitigation not only to enable the community to withstand a variety of disasters, but also to resist, to adapt to the ability of multiple disasters, and has the ability to recover after disaster.

2. Whole process control of disaster:

Disaster prevention and reduction should be run through the whole process of disaster, the different stages should have different ways to deal with the disaster before, during and after the disaster[10].Including disaster prevention and control in order to reduce the probability of disaster, disaster to disaster adaptation in order to reduce disaster losses and the community space and the construction of the building function of the building to complete the reconstruction and recovery as soon as possible.

3. Suitability of community disaster prevention and mitigation strategies:

At present, there are a lot of theoretical research and practical experience in disaster prevention technology in the world. However, China is a developing country, the promotion of Applied Technology and the world's advanced countries still have a certain gap. Therefore, combining the current situation of our country and the current situation of our country, it is very important to choose the economical, feasible and strong implementation of the community disaster prevention and reconstruction strategy.

\section{ACKNOWLEDGMENT}

The International Conference on Architectural Engineering and Civil Engineering is a leading annual conference on Architecture and Civil Engineering fields.

Thank AECE2016 provides a valuable opportunity for researchers and scholars from all over the world to exchange ideas.

\section{REFERENCES}

[1] Li Feng, building safety and disaster prevention and mitigation, Beijing: China Building Industry Press, 2012, 7.

[2] Xu Huzhen, high building fire safety analysis, Journal of Anhui Construction Industry Institute (NATURAL SCIENCE EDITION), 2003, 11 (4): 75 77.

[3] Zhao Qiang, the integration of urban health and ecological community evaluation system: [doctoral dissertation], Tianjin; Tianjin University, 2012, 18 19.

[4] Wang Youwei, Wang Qingqin, Ye Qing, et al. Research on the development of high-rise residential buildings, Beijing: China Building Industry Press, 2012,103.

[5] Zhou Biao, Zhou Ke, Zhou Xiaomeng, et al. Quantitative analysis of comprehensive ability of urban disaster prevention and mitigation, disaster prevention branch Journal of College of technology, 2010, 12 (1): 104 112.

[6] Jin Lei, China's urban disaster risk and the construction of integrated security, China's famous city, 2010 (12): 4 12.

[7] Wang Shaojun, Lv Dong, Ren Chang Xing, et al. Study on the evaluation system of emergency evacuation in crowded places and development, fire science and technology, 2010, 29 (8): 708 710.

[8] Li Xianmei, GIS application in earthquake prevention and mitigation of the development trend of research, College of Disaster Prevention Technique Chinese Journal, 2006, 8 (2): 73 76.

[9] David R. Godschalk, Urban Hazard Mitigation: Creating Resilient Cities,Natural Hazards Review, 2003, 4(3): 136 143.

[10] Timo Tarvainen, Spatial Pattern of Hazards and Hazards Interactions in Europe, In: Philipp Schmidt-Thomé,Natural and Technological Hazards and Riska Affecting the Spatial Development of European Regions Geological Survey of Finland, Special Paper 42: 83 91. 